\title{
Pandangan Lansia tentang Seksualitas pada Lanjut Usia
}

\author{
Hubertus Agung Pambudi ${ }^{1}$, Meidiana Dwidiyanti ${ }^{2}$, Diyan Yuli Wijayanti ${ }^{3}$ \\ ${ }^{1,2,3}$ Fakultas Kedokteran, Universitas Diponegoro Semarang, Indonesia \\ Email: hubert_ap@yahoo.co.id
}

\begin{abstract}
Investigate Sexuality Experiences of The Elderly. The physiological, cognitive and psychosocial changes which occur in the elderly can have an impact on the elderly's decreased ability to meet functional needs, confusion or withdrawal, and an inability to make needs-related decisions. The physical changes include some changes in the appearance, different alterations in internal organ systems, changes in psychological function and nervous system, as well as changes in the sexuality appearance and ability. The purpose of this study was to investigate sexuality experiences of the elderly in the society. This study used a qualitative design with a hermeneutic phenomenological approach. The samples were three elderly people recruited using purposive sampling technique. The steps in analyzing the data included data collection analysis, data reduction, verification, and conclusion. The findings revealed that sexual intercourse in the elderly served a part of worship and efforts made to maintain the family harmony. Based on findings, it is recommended that the health service units work together with the health volunteers of the elderly health service post to provide correct information through health education about sexuality so that the elderly can gain an understanding of sexuality to improve their quality of life.
\end{abstract}

Keywords: Elderly, Sexuality

\begin{abstract}
Abstrak: Pandangan Lansia tentang Seksualitas pada Lanjut Usia. Lanjut usia dengan perubahan yang terjadi secara fisiologis, kognitif dan kesehatan psikososial akan berdampak terhadap berkurangnya kemampuan memenuhi kebutuhan fungsional, kebingungan atau menarik diri, dan ketidakmampuan membuat keputusan yang berkaitan dengan kebutuhan. Perubahan fisik meliputi perubahan penampilan, perubahan yang berbeda pada sistem organ dalam, perubahan dalam fungsi psikologis, perubahan pada sistem syaraf, dan perubahan penampilan dan kemampuan seksualitas. Tujuan penelitian ini adalah untuk mengetahui pengalaman seksualitas pada lansia di masyarakat. Penelitian ini merupakan penelitian kualitatif dengan pendekatan fenomenologi hermeneutic. Sampel penelitian ditentukan dengan menggunakan teknik purposive sampling dengan partisipan lansia sebanyak 3 orang. Tahapan dalam analisis data meliputi analisis pengumpulan data, reduksi data, verifikasi dan penarikan kesimpulan. Hasil penelitian menunjukan bahwa hubungan seksual pada lanjut usia merupakan bagian dari ibadah dan upaya untuk menjaga keharmonisan keluarga. Berdasarkan hasil penelitian, disarankan kepada layanan kesehatan agar bekerjasama dengan kader posyandu lansia untuk memberikan informasi yang benar melalui pendidikan kesehatan tentang seksualitas pada lansia, agar lansia dapat mendapatkan pemahaman seksualitas untuk meningkatkan kualitas hidup mereka.
\end{abstract}

Kata kunci: Lansia, Seksualitas

Setiap manusia di dunia akan mengalami proses menua dan menjadi lanjut usia. Menurut WHO (World Health Organization) lanjut usia adalah mereka yang berusia 60-74 tahun dan menurut UU RI No.13 tahun 1998 tentang kesejahteraan lansia bahwa lanjut usia adalah seseorang yang telah mencapai usia 60 tahun ke atas.(Mujahidullah, 2012) Saat ini, di seluruh dunia jumlah orang lanjut usia diperkirakan ada 500 juta dengan usia rata-rata 60 tahun dan diperkirakan pada tahun 2025 akan mencapai 1,2 milyar. Berdasarkan hasil laporan Infodatin, proyeksi usia pada kelompok lansia di dunia cenderung meningkat dari tahun ke tahun, sejak tahun 2013 jumlah lansia di dunia 13,4\%, tahun 2050 menjadi $25,3 \%$ dan tahun 2100 menjadi $35,1 \%$ (Statistik, 2015). Pertambahan penduduk lansia juga terjadi di Indonesia. Badan Pusat Statistik menyatakan jumlah lansia di Indonesia pada tahun 2015 adalah 9,77\% dari jumlah penduduk dan tahun 2020 mencapai 11,3\%, dan diperkirakan pula bahwa total lansia di Indonesia pada tahun 2020 mencapai 29,12 juta jiwa. Di Indonesia pula terjadi peningkatan populasi lansia dari 14,4 juta jiwa di tahun 2000 dan diperkirakan mencapai 28,8 juta jiwa di tahun 
2020 (Mujahidullah, 2012; Padila, 2013). Tiga provinsi dengan populasi lansia terbesar di Indonesia adalah daerah Istimewa Yogyakarta $13,5 \%$, Jawa Tengah $11,11 \%$, Jawa Timur 10,96\%. (Statistik, 2015). Sumber dari Badan Pusat Statistik Kota Semarang, jumlah lansia yang berumur diatas 60 tahun sejumlah 112.031 jiwa (Badan Pusat Statistik Kota Semarang, 2015). Ada suatu pendapat yang tidak diucapkan, yang sebagian memang benar, pentingnya peranan yang dimainkan oleh seksualitas telah banyak menghilang setelah manusia menjadi tua. Seksualitas terbayangkan berkaitan dengan kecantikan fisik atau adanya sedikit daya tarik. Kedua hal ini sebagian besar menghilang bersamaan dengan semakin lanjutnya usia karena adanya perubahan-perubahan pada kulit serta susunan jaringan ikat dan lemak (Mujahidullah, 2012); (Irianto, 2014). Gagasan mengenai aktviatas seksual dalam usia lanjut cenderung menyalahi perasaan estetik. Manusia memilih untuk tidak memperdulikan bahwa hubungan seksual dapat menjadi suatu bentuk komunikasi non verbal, yang lebih penting daripada keadaan luarnya (Irianto, 2014).

Seksualitas berdasarkan WHO adalah suatu aspek inti manusia sepanjang hidupnya dan meliputi seks, identitas dan peran gender, orientasi seksual, erotisisme, kenikmatan, kemesraan dan reproduksi. Seksualitas dialami dan diungkapkan dalam pikiran, khayalan, gairah, kepercayaan, sikap, nilai, perilaku, perbuatan, peran dan hubungan. Sementara seksualitas dapat meliputi semua dimensi ini. Tidak semuanya selalu dialami atau diungkapkan. Seksualitas dipengaruhi oleh interaksi faktor biologis, psikologis, sosial, ekonomi, politik, budaya, etika, hukum, sejarah, religi dan spiritual (World Health Organization, 2006).

Hasil pengkajian aplikasi komunitas pada tanggal 27 Oktober-4 Nopember 2016 terhadap 41 Lansia yang berpasangan yang berumur 60-74 tahun di Kelurahan Pedalangan Kecamatan Banyumanik Semarang, dengan intrumen pengkajian kuesioner berdasarkan Teori Self Care. Pertanyaan berdasarkan nilai dan budaya yang ada di masyarakat, lanjut usia masih membutuhkan hubungan suami istri $58.54 \%$ lansia, kadangkadang dalam melakukan hubungan suami istri,19.51\% lansia jarang melakukan hubungan suami istri, $14.63 \%$ lansia tidak pernah melakukan hubungan suami istri dan $7.32 \%$ lansia selalu melakukan hubungan suami istri. Hasil pengkajian dengan pertanyaan lanjut usia tidak perlu berhubungan suami istri didapatkan hasil, 17 lansia $(41,46 \%)$ menjawab kadang- kadang, 13 lansia $(31,71 \%)$ menjawab jarang, 9 lansia $(21,95 \%)$ menjawab tidak pernah dan 2 lansia (4,88\%) menjawab selalu. Hasil pengkajian lansia berdasarkan percaya hubungan suami istri pada usia lanjut dapat membuat awet muda, 16 lansia (39.02\%) menjawab selalu, 13 lansia $(31,71 \%)$ menjawab kadang-kadang, 7 lansia (17.07\%) menjawab tidak pernah dan 5 lansia (12.20\%) jarang.

Sampai saat ini, seksualitas orang tua belum dibahas secara terbuka dan bebas di banyak negara, termasuk Korea. Kebanyakan orang menganggap bahkan pemikiran seksualitas orang tua tidak masuk akal. Pikiran dari orang Korea lebih acuh tak acuh atau negatif tentang seksualitas pada wanita lanjut usia dibandingkan pria. Karena mereka percaya kebajikan monogami, wanita lanjut usia cenderung tidak menikah lagi saat mereka kehilangan pasangan mereka (Lee, Kwon, Kim, \& Moon, 2007).

Ulasan pada jurnal Sexuality in Older Age: Essential Considerations for Health Care Professionals menggambarkan fakta bahwa banyak orang tua menikmati kehidupan seks yang aktif dan memeriksa bukti terhadap persepsi umum dari 'aseksual' usia tua. Ini menawarkan gambaran bukti bagi para profesional kesehatan yang sebelumnya tidak terlalu menganggap penting seksualitas pasien mereka yaitu lansia. Hal ini juga menjelaskan beberapa masalah seksual yang dihadapi oleh orang-orang yang lebih tua, terutama kesulitan- kesulitan yang dialami dalam mengungkapkan masalah tersebut kepada profesional kesehatan (Taylor \& Gosney, 2011)

Penelitian akhir-akhir ini menunjukkan banyak golongan lansia tetap menjalankan aktifitas seksual sampai usia yang cukup lanjut, dan aktifitas tersebut hanya dibatasi oleh status kesehatan dan ketiadaan pasangan. Aktifitas dan perhatian seksual pasangan suami istri lansia yang sehat berkaitan dengan pengalaman seksual kedua pasangan tersebut sebelumnya (Martono \& Pranarka, 2009).

Kesehatan seksual merupakan suatu hal yang sukar untuk diartikan, karena kebanyakan masyarakat menganggap kesehatan seksual adalah suatu peristiwa yang sulit untuk dijelaskan sehingga menimbulkan suatu anggapan yang salah. World Health Organization, mendefinisikan kesehatan seksual sebagai pengintegrasian aspek somatik, emosional, intelektual, dan aspek sosial dari kehidupan seksual dengan cara yang positif untuk memperkaya pengetahuan seksualnya dalam bentuk kepribadian, dan perasaan cinta (Berman et al, 2015). 
Kehilangan seksualitas bukan merupakan aspek penuaan yang tidak dapat dihindari dan sebagian besar orang yang sehat tetap aktif secara seksual secara teratur sampai usia lanjut. Namun proses penuaan memang membawa perubahan tertentu dalam respon seksual fisiologis pria dan wanita, dan disertai sejumlah medis yang menjadi lebih prevalen pada usia lanjut yang berperan penting terjadinya gangguan seksual patogen terhadap lansia (Stanley \& Beare, 2016).

Berdasarkan hasil wawancara dengan perawat pemegang program lansia di Kelurahan Pedalangan Kecamatan Banyumanik Semarang wilayah kerja Puskesmas Padangsari Banyumanik Semarang, tidak ada keluhan atau cerita dari lansia tentang kehidupan hubungan suami istri. Hal ini menunjukan tertutupnya pandangan hubungan suami istri pada lansia dalam menjalin kehidupan di usia lanjut.

Tujuan penelitian ini untuk mengetahui pengalaman lansia tentang seksualitas pada lanjut usia di masyarakat Kelurahan Pedalangan wilayah kerja Puskesmas Padangsari Banyumanik Semarang.

\section{METODE}

Penelitian ini menggunakan desain penelitian kualitatif dengan pendekatan fenomenologi hermeneutic, suatu pendekatan yang mengasumsikan temuan-temuan risetnya tidak murni hasil deskripsi, tetapi lebih interprestasi peneliti (Afiyanti \& Nurahmawati, 2014) (Creswell, 2015).

Strategi pemilihan sampel yang digunakan dalam penelitian ini adalah criterion sampling yaitu bertujuan untuk memperoleh sampel yang memenuhi kriteria tertentu dan berguna untuk menjamin kualitas sampel (Creswell, 2015). Dalam hal ini partisipan yang diambil lansia berusia 60-74 tahun yang mempunyai pasangan hidup yang sah dan bersedia menjadi partisipan dengan memberikan persetujuan, mampu dan mau menceritakan persepsi seksualitas.

Instrumen penelitian yang digunakan adalah kuesioner. Kuesioner yang digunakan adalah pertanyaan tentang pandangan lansia tentang seksualitas pada lanjut usia, dan cara pengambilan data dengan melakukan wawancara yang mendalam kepada partisipan lansia sesuai dengan kriteria yang ditetapkan.

Membuat transkrip data, menyusun hasil wawancara dengan cara mendeskripsikan hasil rekaman dalam bentuk verbatim, kedua menilai keakuratan hasil wawancara dengan mendengarkan kembali hasil wawancara dan mencocokan dengan membaca transkrip verbatim serta mengintegrasikan hasil catatan lapangan kedalam transkrip.

Membaca hasil transkrip berulang-ulang, untuk mendapatkan pemahaman yang tepat dari hasil wawancara, untuk mengidentifikasi pernyataan yang bermakna dari setiap partisipan. Pernyataan dari setiap partisipan yang bermakna berdasarkan catatan lapangan saat dilakukan penelitian disebut sebagai kata kunci.Mengulang semua proses untuk semua hasil transkrip partisipan yang kemudian menentukan kategori. Semua pernyataan yang memiliki makna yang sama atau hampir sama dijadikan dalam satu kategori.

Memahami berbagai kategori secara utuh dan menelusuri tema yang kemungkinan muncul. Kategori yang sudah didapatkan, menjadikan pernyataan yang bermakna dan saling berhubungan sehingga dapat dijadikan sub tema. Kategori yang sejenis dan terkait dirumuskan dalam bentuk tema. Mengintegrasikan hasil secara keseluruhan kedalam bentuk deskriptif naratif yang lengkap, sistematis, jelas dalam hasil penelitian. Mengklarifikasi hasil diskriftif analisis data yang telah dibuat dengan mengembalikan kepada partisipan untuk memastikan apakah sudah sesuai dengan apa yang disampaikan kepada peneliti. Pada tahap ini peneliti memvalidasi kepartisipan dengan datang kembali ke rumah partisipan.

Strategi memperoleh keabsahan atau validitas data dengan menggunakan trianggulasi dengan melakukan Member Check/ Feedback Partisipan, peneliti kembali mencocokkan pemahaman dan interprestasi data yang dihasilkan kepada pemahaman partisipan lansia. Peneliti juga mengamati langsung berbagai reaksi pada partisipan lansia terhadap data yang dihasilkan dari wawancara dan meminta para partisipan memberi tanggapan tambahan terhadap hasil data tersebut (Afiyanti \& Nurahmawati, 2014; Moleong, 2016)

\section{HASIL}

Tabel 1. Karakteristik Partisipan

\begin{tabular}{|c|c|c|c|c|}
\hline $\begin{array}{c}\text { Nama } \\
\text { Partisipan }\end{array}$ & Usia & $\begin{array}{c}\text { Jenis } \\
\text { Kelamin }\end{array}$ & Pekerjaan & Alamat \\
\hline P1 (Ny. S) & $\begin{array}{l}64 \\
\text { tahun }\end{array}$ & Perempuan & $\begin{array}{l}\text { Ibu rumah } \\
\text { tangga }\end{array}$ & Semarang \\
\hline P2 (Ny. V) & $\begin{array}{l}60 \\
\text { tahun }\end{array}$ & Perempuan & Pensiunan & Semarang \\
\hline P3 (Tn. S) & $\begin{array}{l}64 \\
\text { tahun }\end{array}$ & Laki-laki & Pensiunan & Semarang \\
\hline
\end{tabular}


Partisipan pertama seorang lansia perempuan, seorang ibu rumah tangga dan berjalan kelontong di rumahnya, tinggal berdua dengan suaminya berumur 65 tahun. Partisipan masih aktif dalam kegiatan posyandu lansia, rumahnya tiap hari Rabu minggu kedua digunakan untuk Posyandu Lansia, tiap hari Minggu pagi selalu rutin mengikuti senam kesegaran jasmani bertempat juga di halaman dan dijalan depan rumah partisipan, partisipan juga aktif mengikuti kegiatan lansia di Poltekkes Tembalang. Pasangan partisipan seorang pensiunan pegawai swasta, pasangan mengalami sakit DM, pasangan masih rajin bekerja di kebun dan berolah raga jalan kaki tiap pagi mengitari kampung selama 30 menit - 60 menit.

Partisipan kedua seorang lansia perempuan, seorang ibu rumah tangga sambil jualan warung makan di halaman rumahnya, partisipan pensiunan dari pegawai swasta, tinggal serumah dengan pasangannya bersama dengan anaknya yang berumur 23 tahun. Partisipan dalam keseharian masih aktif dalam kegiatan kerohanian di gereja, seperti paduan suara, bakti sosial, tidak pernah ikut senam lansia yang diadakan tiap hari Minggu. Dirumah partisipan membantu menyiapkan masakan yang akan di jual di warung. Pasangan partisipan berumur 62 tahun, masih aktif dalam bidang pembangunan, sebagai seorang kontraktor.

Partisipan ketiga seorang lansia laki - laki, pensiunan Pegawai Negeri Sipil, tinggal satu rumah dengan pasangannya dan cucunya yang masih berumur 9 tahun. Partisipan masih aktif pergi ke Masjid dan melakukan olah raga jalan kaki tiap pagi, untuk kegiatan senam lansia partisipan kadang - kadang ikut datang, tetapi tidak rutin mengikutinya. Keseharian partisipan melakukan kegiatan rumah, dan juga mengantar dan menjemput cucunya sekolah. Pasangan partisipan berumur 63 tahun, seorang pensiunan dan masih aktif dalam memasak dan menyiapkan kebutuhan rumah tangga untuk suami dan keluarganya.

Temuan pada penelitian dengan pertanyaan pandangan partisipan terhadap seksualitas pada lansia menunjukkan bahwa semua partisipan menganggap suatu hal yang wajar sebagai bentuk kebutuhan walaupun kuantitasnya sudah tidak seperti waktu muda. Partisipan juga menganggap bahwa hubungan seksual walaupun pada lanjut usia masih dianggap sebagai hal yang wajar. Lansia yang menjadi partisipan ini juga menyadari bahwa dengan usia yang sudah lanjut, bentuk seksualitas juga sudah berbeda dan lebih merasakan sebagai bentuk kasih sayang dan perhatian. Partisipan juga menyatakan bahwa bentuk-bentuk seksualitas masa lanjut usia dengan lebih mengedepankan perhatian dan kasih sayang ini ternyata juga mampu memberikan kepuasan tersendiri bagi partisipan dan pasangannya. Partisipan juga memahami sepenuhnya bahwa hubungan seksualitas suami istri yang sah adalah merupakan bagian dari ibadah. Sehingga walaupun sudah lanjut usia namun tetap melakukan hubungan tesebut walaupun dengan intensitas yang sudah berkurang namun dilakukan dengan tujuan memberikan perhatian dan kasih sayang pada pasangan. Usia lansia dengan keterbatasan fisik memang membuat pasangan lansia dalam melakukan hubungan seksualitas mengalami penurunan, namun demikian partisipan tetap berupaya untuk memberikan kepuasan terhadap pasangannya masing-masing karena hal itu merupakan satu kebahagiaan tersendiri untuk bisa memberikan rasa kepuasan kepada pasangan.

\section{PEMBAHASAN}

Hasil penelitian menemukan tema hubungan seksualitas dalam keluarga merupakan bentuk ibadah dan keharmonisan lansia. Kategori pada partisipan ditemukan masih perlu seksualitas, bentuk seksualitas, partisipan masih bisa merasakan kepuasan, merasa mendapat perhatian, lansia menyadari tidak menyalahi aturan agama dan norma masyarakat, menganggap hubungan seksualitas suami istri merupakan bagian dari ibadah. Partisipan mengakui seksualitas menjaga keharmonisan keluarga, masing-masing berupaya untuk memberikan kepuasan pasangan, perlunya ketenangan batin yang didukung kesehatan badan, ekonomi dan lingkungan yang nyaman.

Pemahaman lanjut usia terhadap fungsi seksualitas itu dipahami sebagai aspek fisik, aspek psikologis, aspek sosial, aspek persaudaraan dan kewajiban suami istri atau suami, maka respon partisipan yang digambarkan benar-benar memahami tentang fungsi seksualitas di lanjut usia. Pemahaman fungsi seksualitas berdasarkan pemahaman lanjut usia teridentifikasi adanya hubungan berbagai konteks yang meliputi hubungan fisik, hubungan psikologis, hubungan sosial, hubungan persaudaraan dan hubungan pernikahan. Kebutuhan seksual merupakan kebutuhan dasar yang penting. Hal ini berkaitan dengan fisiologis yakni kebutuhan seks dan pemenuhan kebutuhan psikologis yakni dicintai dan mencintai. Kebutuhan seksual dimasukkan dalam salah satu prioritas tingkat kebutuhan dalam klasifikasi 
tingkat kebutuhan dasar Maslow (Potter, Perry, Stockert, \& Hall, 2016). Ada perbedaan pemahaman yang dilatar belakangi oleh karakteristik jenis kelamin, dimana partisipan yang berjenis kelamin laki-laki memahami fungsi seksualitas itu hanya hubungan fisik dan hubungan persaudaraan sedangkan partisipan perempuan yang mempunyai sifat menerima memahaminya sebagai sebuah hubungan pernikahan sebagai kewajiban seorang istri kepada suami dan hubungan sosial (Ropei, 2010). Perilaku seksualitas dilakukan sesuai kehidupan pribadinya sebagai moral dan pengalamannya, akibatnya individu mempunyai perbedaan dalam pemahaman, keyakinan dan nilai seksual mereka. Perubahan fungsi seksualitas yang teridentifikasi penelitian adalah adanya perubahan ekspresi seksualitas, perubahan kegiatan seksualitas dan penyebab perubahan fungsi seksualitas pada partisipan. Perubahan ekspresi seksualitas pada partisipan berubah menjadi tambah sayang dan rasa sayang berubah menjadi kekerabatan. Perubahan kegiatan seksualitas pada partisipan meliputi perubahan dalam frekuensi, kekuatan, keinginan dan usia dirasakan perubahan. Ekspresi seksualitas itu sangat serupa dengan perilaku sosial lainnya yaitu seseorang akan berperilaku sesuai dengan mereka dihargai untuk berperilaku (Potter et al., 2016).

Partisipan juga mengakui bahwa hubungan seksualitas pada masa lanjut usia bukan hanya sebagai pemuas nafsu syahwat saja, namun hal ini dilakukan sebagai bentuk atau upaya untuk menjaga keharmonisan keluarga. Para partisipan yang hakekatnya adalah lansia menyadari bahwa kehidupan seksualitas melekat erat dalam kehidupan sosial yang memberikan kesempatan dan batasan sehinga ekpresi seksualitas partisipan lebih menekankan kepada rasa sayang dan keluarga. Ekspresi fungsi seksualitas pada lanjut usia sudah mengalami perubahan dimana jenis dan aktivitas seksualitasnya lebih diaktualisasaikan pada aspek kedekatan dengan pasangan, pertemanan, komunikasi intim, dan hubungan fisik mencari kesenangan.

Hasil penelitian menemukan bahwa bentuk aktivitas seksual yang dilakukan oleh partisipan dengan pasangannya lebih menonjolkan bentuk perhatian dan kasih sayang, seperti hanya dalam bentuk bergandengan tangan, bersentuhan atau sekedar menggoda pasangan. Hasil penelitian ini sejalan dengan penelitian yang dilakukan oleh Purnamasari, Margono dan Setiyawati yang menemukan bahwa terjadi perubahan bentuk seksualitas pada lansia yang menyatakan bahwa masih melakukan aktivitas seksual non intercourse, mereka mengatakan masih melakukan aktivitas seksual lain seperti berciuman, meraba dan berpelukan, meskipun sudah tidak melakukan hubungan seksual (Purnamasari, Margono, \& Nanik Setyowati, 2014).

Hasil penelitian ini juga menemukan bahwa hubungan seksualitas antara suami dan istri yang sah adalah bagian dari ibadah. Sebagaimana Hadist yang diriwayatkan Muslim menyatakan bahwa "Bukankah apabila seseorang melampiaskan syahwat nya pada tempat yang haram dia mendapatkan dosa? Begitu pula jika dia melampiaskan syahwatnya tersebut pada tempat yang halal, maka baginya pahala". Kondisi ini menunjukkan bahwa sebenarnya bagi sepasang suami-istri, berhubungan badan (jima') merupakan kebutuhan yang tidak terlewatkan, dan bisa menjadi salah satu tolak ukur kebahagiaan dalam kehidupan rumah tangga. Bahkan bukan hanya bernilai kebutuhan, hubungan ini pula pastinya merupakan ibadah di hadapan Allah dan Dia akan memberikan bagi pelakunya pahala shadaqah. Rasulullah shallallahu 'alaihi wasallam bersabda ketika ditanya tentang pernyataan beliau bahwa hubungan suami-istri (jima') sedangkan hubungan badan itu adalah melampiaskan syahwat, namun ini termasuk kedalam bentuk shadaqah.

Berdasarkan hasil penelitian pada partisipan yang dikaitkan dengan teori self care, ditemukan bahwa pada partisipan ke dua dan ke tiga mampu menunjukkan kemampuannya dalam beraktifitas seksual dengan pasangan secara baik. Artinya partisipan ke dua dan ke tiga masih dalam kategori Universal Self Care Requisters, partisipan masih mampu dalam mencapai perawatan diri dalam menjalani kehidupan seksualitasnya. Kondisi yang berbeda ditemukan pada partisipan pertama bersama pasangannya, dimana pasangan partisipan pertama yang menderita penyakit DM ternyata mengganggu aktifitas seksual diantara keduanya. Partisipan dalam kategori Development Self Care Requisiters, berhubungan perubahan dari pasangan dalam kemampuan seksualitasnya. Partisipan berusaha mengatasi dampak dari situasi pasangan dengan melakukan penerimaan bahwa seksualitas merupakan ibadah seorang istri kepada suaminya, dan untuk menjaga keharmonisan rumah tangga. Partisipan dalam sistem pelayanan keperawatan berdasarkan Orem, termasuk dalam kategori sistem Supportif dan Edukatif berupa bantuan dukungan pendidikan kesehatan pada lansia, dengan harapan partisipan dapat tetap secara mandiri 
menjalani hubungan seksualitas dengan pasangan secara baik (S, Hamid, \& Ibrahim, 2017).

\section{SIMPULAN}

Hubungan seksual pada lanjut usia merupakan bagian dari ibadah dan upaya untuk menjaga keharmonisan keluarga.

\section{SARAN}

Pendidikan seksualitas pada lansia dimasukan dalam kurikulam pendidikan mata kuliah keperawatan lansia, sehingga mahasiswa mampu memberikan pelayanan kepada lansia pada aplikasi praktek keperawatan di komunitas dengan komprehensif. Diharapkan layanan kesehatan mampu bekerja sama dengan kader posyandu lansia memberikan informasi yang benar melalui pendidikan kesehatan mengenai seksualitas pada lansia, agar lansia dapat mendapatkan pemahaman seksualitas pada masa lanjut usia, untuk meningkatkan kualitas hidupnya. Peneliti selanjutnya diharapkan dapat melakukan penelitian faktor-faktor yang berhubungan dengan seksualitas pada lansia, pengembangan intervensi keperawatan untuk masalah seksualitas pada lansia, pelatihan kader dengan dampak terhadap pelayanan kesehatan pada lansia.

\section{DAFTAR PUSTAKA}

Afiyanti, Y., \& Nurahmawati, I. 2014. Metedologi Penelitian Kualitatif Dalam Riset Keperawatan (1st ed.). Jakarta: PT Raja Grafindo Persada.

Badan Pusat Statistik Kota Semarang. 2015. Jumlah Penduduk Menurut Kelompok Umur. Semarang.

Berman, A., Kozier, B., Snyder, S. J., Snyder, C., Erb, G. L., Frandsen, G., \& Pearson. 2015. Kozier and Erb's Fundamentals of Nursing: Concepts, Process, and Practice. Pearson Education.

Creswell, J. W. 2015. Penelitian Kualitatif dan Desain Riset: Memilih di Antara Lima Pendekatan. (S. Z. Qudsi, Ed.) (3rd ed.). Yogyakarta: Pustaka Pelajar.

Irianto, K. 2014. Seksologi Kesehatan. Bandung: Penerbit Alfabeta.

Lee, K. J., Kwon, M. S., Kim, M. J., \& Moon, S. M. 2007. A Study on Knowledge and Attitudes regarding sexuality of elderly people in Korea. Journal of Korean Academy of Nursing.

Martono, H., \& Pranarka, K. (2009). Ilmu Kesehatan Usia Lanjut (4th ed.). Jakarta: Balai Penerbit FKUI.

Moleong, L. J. 2016. Metodologi Penelitian Kualitatif (Edisi Revi). Bandung: PT. Remaja Rosdakarya.

Mujahidullah, K. 2012. Keperawatan Geriatrik. Yogyakarta: Pustaka Pelajar.
Padila. 2013. Buku Ajar Keperawatan Gerontik. Yogyakarta: Nuha Medika.

Potter, P. A., Perry, A. G., Stockert, P., \& Hall, A. 2016. Fundamentals of Nursing - EBook (9th ed.). New York: Elsevier Health Sciences.

Purnamasari, D., Margono, \& Nanik Setyowati. 2014. Geriatric Sexual Activity. Ilmu Kebidanan, II.

Ropei, O. 2010. Pengalaman Perubahan Fungsi Seksualitas pada Lanjut Usia di Kota Cimahi Studi Fenomenologi.

S, A. Y., Hamid, \& Ibrahim, K. 2017. Pakar Teori Keperawatan dan Karya Mereka (8th Indonenesia). Indonesia: Elsevier Singapore.

Stanley, M., \& Beare, P. G. 2016. Buku Ajar Keperawatan Gerontik (2nd ed.). Jakarta: EGC.

Statistik, B. P. 2015. Statistik Penduduk Lanjut Usia 2014 Hasil Survei Sosial Ekonomi Nasional. Jakarta.

Taylor, A., \& Gosney, M. A. 2011. Sexuality in Older Age: Essential Considerations for Health Care Professionals. Age and Ageing.

World Health Organization. 2006. Defining Sexual Health: Report of technical consultation on sexual health 28-31 January 2002, Geneva. Sexual Health Document Series. 